\title{
Emergence of the arterial switch procedure for transposition of the great arteries and the potential cost of surgical innovation
}

\author{
Craig S. Broberg, MD, MCR, ${ }^{\mathrm{a}}$ Irving Shen, MD,${ }^{\mathrm{b}}$ Victor Menashe, $\mathrm{MD},{ }^{\mathrm{c}}$ and Albert Starr, $\mathrm{MD}^{\mathrm{a}}$
}

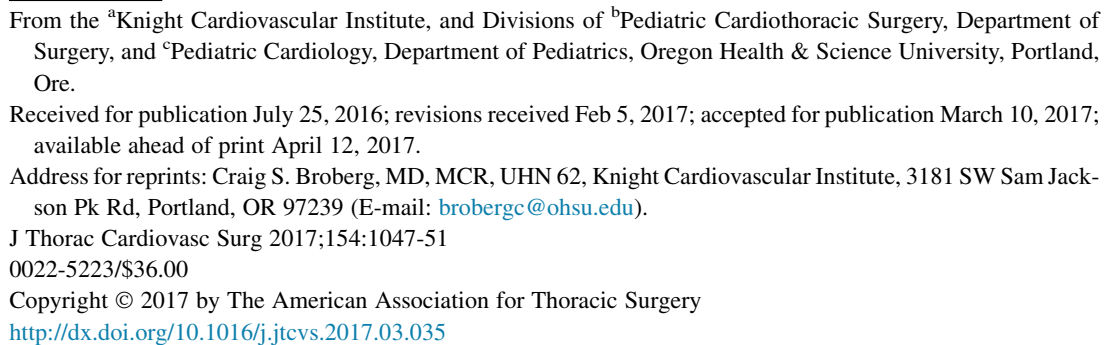

"Human progress is neither automatic nor inevitable... Every step toward the goal of justice requires sacrifice, suffering, and struggle." -Martin Luther King, Jr

Surgical innovation has played an extensive role in the development of our modern healthcare. The ethics of this innovation involve the surgeon making the best decision possible on behalf of the patient. The arterial switch operation (Jatene procedure), which revolutionized the care of individuals born with dextro-transposition of the great arteries (D-TGA), emerged when an alternative surgical palliation had been successfully practiced for approximately 20 years. A review of published mortality for D-TGA operations during the years of transition from atrial to arterial switch methodology shows that, generally, published mortality for the arterial switch remained higher than for atrial switch procedures over its first decade. Although there is a lack of direct comparisons, particularly accounting for surgical timing, the review suggests that the newer procedure was likely performed in infants for whom a Mustard or Senning approach was a lower-risk alternative. This experience is demonstrative of the learning-curve cost of a new procedure in terms of poorer outcomes and raises questions regarding the appropriateness of ethical scrutiny of surgical innovation in today's era. We review the emergence of the arterial switch over time, with a focus on perioperative mortality data, and discuss the ethical lessons from this beneficial change in practice.

\section{EARLY SUCCESSES IN SURGERY FOR TRANSPOSITION OF THE GREAT ARTERIES}

The first arterial switch operation was performed in 1952 by Mustard in a 3-month-old girl, who died in the operating room. ${ }^{1,2}$ With little alternative, Mustard and colleagues $^{3}$ made 7 more attempts and Bailey made 1

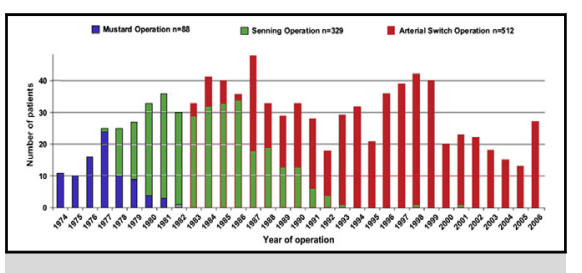

Transition from atrial to arterial switch over time for transposition of the great arteries.

\section{Central Message}

The history of the arterial switch operation, which emerged when a lower-risk option was available, provides a context for considering the ethics of surgical innovation in the current era.

See Editorial Commentary page 1052.

attempt at the arterial switch in neonates and young infants that same year, ${ }^{2}$ all unsuccessfully. Three years later, Senning attempted the procedure with the same results. ${ }^{2}$ With these published experiences, the approach was abandoned and attention was turned to using pulmonary venous manipulation as had been tried in animal models. ${ }^{2}$ In 1957, Senning $^{4}$ performed the first successful atrial redirection procedure in a human. Others followed with modifications, notably by Mustard and colleagues. ${ }^{5}$ From these 2 surgeons, the atrial switch procedures that bore their names were enthusiastically adopted. For approximately 20 years, the atrial switch approach was the only option $^{2,6}$ (Figure 1). The results, although imperfect, were favorable, and survival was the rule rather than the exception. In a 1972 series of 200 cases, mortality was remarkably $18 \%{ }^{7}$

In 1976, Jatene and colleagues ${ }^{8}$ attempted the 10 th recorded arterial switch operation in a 3-month-old patient. Both coronary artery ostia were reimplanted. ${ }^{8}$ Although the outcome was again a fatality, the patient died on postoperative day 3 rather than intraoperatively. This led to a second attempt in a 1.5-month-old patient with a coexistent ventricular septal defect (VSD). The patient survived, the first survivor of an anatomic repair of D-TGA ${ }^{8} 24$ years after the first attempt. News of the success spread quickly. Eager surgeons throughout the world soon adopted the technique. ${ }^{1}$ By 1979, multiple successful operations have been performed at many institutions following Jatene 


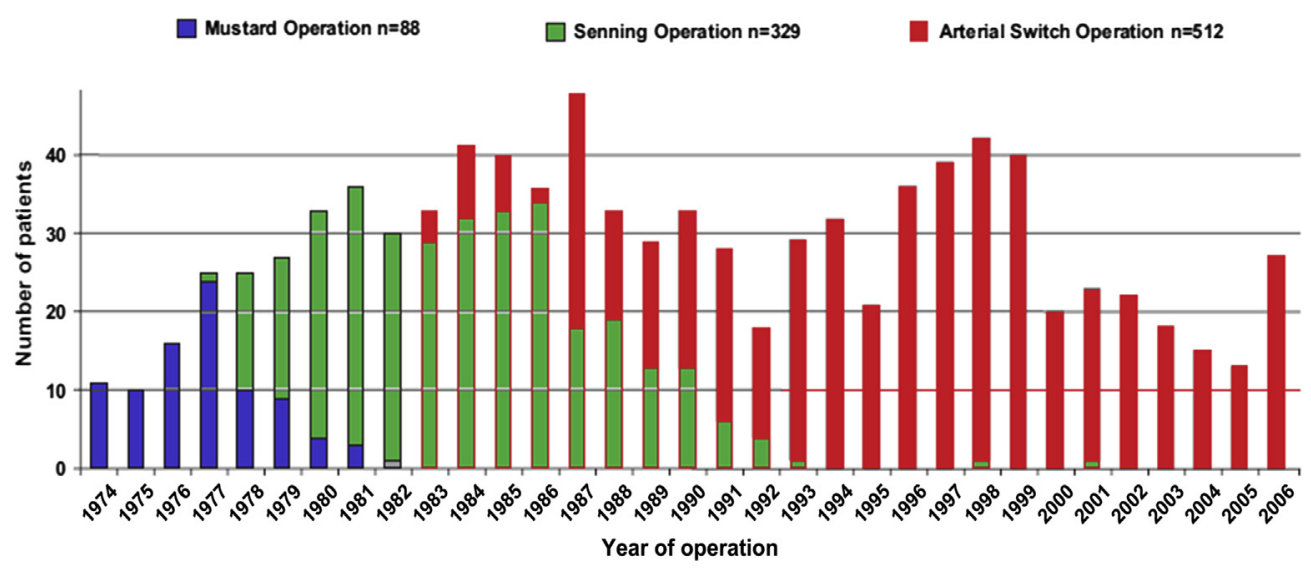

FIGURE 1. The years of transition from atrial switch (Mustard or Senning procedures) to the atrial switch operation (Jatene procedure) for infants born with D-loop transposition of the great arteries, from a single center are representative of similar changes at centers across the world. For most of these years, the published mortality from the arterial switch was higher than the other methods. Reprinted from Horer and colleagues. ${ }^{6}$

and colleagues ${ }^{8}$ general methods. Most also would adopt Lecompte and colleagues' ${ }^{9}$ modification published in 1981.

\section{COMPARATIVE MORTALITIES}

In retrospect, enthusiasm for the new approach was, although understandable, counter to available outcome data. Two small early series reported 5 deaths in 15 surgeries, or 33\% mortality. ${ }^{10,11}$ Although far better than attempts in prior decades, this was substantially higher than the $17 \%$ operative mortality for the atrial switch published earlier. ${ }^{12}$

The major problem was coronary ostial manipulation. Coronary anomalies, which were frequently encountered during surgery, required unplanned modifications. Approximately $20 \%$ of intended arterial switch procedures were abandoned intraoperatively, reverting to an atrial switch, usually due to unexpected coronary anomalies. ${ }^{6}$ With published results in 1981, 5 years in, one group stated, "At the present time, there seems to be no good reason to alter our surgical policy in this group of patients."13

Adoptive trends continued through the early 1980s, a period of more widespread use of the arterial switch. However, despite a decade of developing technique, survival comparisons still did not favor the arterial switch, even at a single institution. In 1986, Quaegebeur and colleagues ${ }^{14}$ reported that operative mortality for an arterial switch was $12 \%$, although the Mustard/Senning experience also had improved. Average mortality was down to $9 \%$ in studies published from 1980 to 1985 involving 796 reported cases.

In 1988, Norwood and colleagues ${ }^{15}$ reported 1-week postoperative mortality from the arterial switch of $18 \%$ versus $4 \%$ for a Mustard operation. Even survival up to 2.5 years beyond the perioperative period, reported in a multicenter study from the Canadian Heart Surgeons' Society, was still favorable for the more traditional Mustard approach $\left(10 \%\right.$ vs $22 \%$ for the arterial switch). ${ }^{15}$ Yet, with the decreasing mortality and hope of better longterm prospects for survivors, surgeons continued to press on with the arterial switch option. The authors commented that experience "suggests the possibility that the late results will be better than after the atrial switch repair." 15 This indeed was the widely held belief, ultimately borne out, that carried the momentum in favor of the arterial switch even while admitting that the early mortality data did not yet conclusively support it.

Yet also in 1988, pooled results of institutions from the Congenital Heart Surgeons' Society were published. ${ }^{16}$ Overall 1-year mortality was $19 \%$, which included 5 deaths among patients intended for the atrial switch operation waiting for surgery. Whether initially intended for atrial or arterial switch surgery, $7 \%$ of infants were eventually converted to the alternate strategy. The surgical approach did not differentiate survivors, although arterial switch outcomes were worse at institutions considered to be high risk, highlighting the importance of the early learning curve. The study demonstrated the safety of neonatal surgery, because the majority of arterial switch operations were performed within 2 weeks of birth and no doubt fortified further use of the methods.

Steady improvements in operative mortality were published through the early 1990s for both surgeries, approximately $10 \%$ to $11 \%$ for either. ${ }^{17}$ However, reoperations for the arterial switch procedure were common, ${ }^{6}$ and both hospital mortality and reoperation rates were still not favorable compared with the Senning procedure (but were vs Mustard). ${ }^{6}$ By the mid-1990s, the de facto operative strategy for D-TGA in most Western institutions was the arterial switch.

Most published studies in the late 1990s reported similar mortality between the 2 approaches, yet mortality was still high outside of North America and Europe. For example, arterial switch mortality of $42 \%$ in 267 cases was reported 
in Japan, ${ }^{18}$ compared with $18 \%$ of 79 atrial switch operations in Russia. ${ }^{19}$ With these outcomes in mind, some at the time argued that the atrial switch still should be considered the procedure of choice if experience was low, citing a higher risk of early death with the arterial switch. ${ }^{20}$ Longterm outcomes were still somewhat comparable for many years.

By the end of the century, definitive figures proving better mortality from the arterial switch were still elusive. In a comparison of 222 atrial switch surgeries versus 80 arterial switch surgeries performed from 1973 to 2000, the arterial switch still had worse early mortality (most, no doubt, reflecting earlier eras), but after approximately 15 years of follow-up, there was better freedom from ventricular dysfunction and heart failure medications. ${ }^{21}$ In a 1999 review of the arterial switch after 15 years, recognizing equipoise in survival data and the growing improvements over time, Massin ${ }^{22}$ concluded, with less resolution than one might expect, "it is reasonable to accept this operation as the procedure of choice."

In 2000, 24 years after Jatene and colleagues' first success, an exemplary publication from a single center presented a transparent analysis of the risks in adopting the arterial switch as an institution. ${ }^{23}$ Bull and colleagues' data $^{23}$ demonstrated a clear increase in overall mortality from D-TGA surgery during the period of transition due to adoption of the arterial switch, whereas surgical success from another congenital heart lesion was progressively lower over this same time frame. By using statistical models based on outcome data, they demonstrated that expected survival curves for the 2 procedures theoretically would cross at approximately age 28 years. On the basis of their projections and statistical justification for the arterial switch in light of the outcome disparities documented, they made an institutional decision to abandon the atrial switch in favor of the arterial switch.

\section{CURRENT OUTCOMES AND LONG-TERM CONSIDERATIONS}

Today, the arterial switch is unquestionably the favored approach. Mortality for the arterial switch, based on more than 3000 operations performed in 2005 , is down to $2.2 \%{ }^{24}$ The arterial switch outcomes are favorable for both exercise capacity and clinical status, although ongoing concerns about coronary perfusion remain. Furthermore, the cited "unacceptable morbidity" 22 after an atrial switch has been observed.

Even so, in some regions mortality is still unfavorable for the arterial switch. In 2011, a single center in a developing nation published arterial switch mortality of $47 \%$ versus only $25 \%$ for the atrial switch. ${ }^{25}$ Late referrals resulting in deconditioning of the morphologic left ventricle and low procedural volume were cited as factors. Even a recently published large series of D-TGA surgery from the International Quality Improvement Collaborative in so-called developing nations across the globe fits the pattern. ${ }^{26}$ The majority $(80 \%)$ of the 778 cases in this contemporary study underwent an arterial switch, whereas 101 underwent an atrial switch procedure. Although reasons for the surgical choice were not available, the mortality for a simple arterial switch was $14 \%$, and higher when a VSD was closed. Meanwhile, the atrial switch mortality was $11 \%$ with or without a VSD, lower but not statistically different. Mortality was associated with the need for VSD closure, an underweight or premature infant, and the hospital procedural volume. It did not differ by choice of surgery or age at the time of operation. There were fewer neonatal surgeries than would be expected, raising appropriate questions about how the timing of surgery factors into the surgeon's decision about which operation to perform or the outcome, an issue that potentially confounds the comparisons of published mortality cited earlier. Still, the authors restate the "historical certainty" of the learning curve for surgical treatment of transposition of the great arteries, which is still finding its way across the world. ${ }^{26}$

\section{ETHICAL CONTEXT OF SURGICAL INNOVATION}

Just as battleground losses are an inevitable price of military victory, advancements in the practice of medicine inevitably result in casualties along the way. Lessons learned from the well-intentioned yet imperfect treatment of patients have gradually led to successes for the overall population. The arterial switch fits this pattern. In our view, considering the published literature, the arterial switch experience demonstrates that, for several years, the published mortality remained higher than a well-established lower mortality option available to many patients. This allows a framework for considering ethics of surgical innovation.

In today's care environment, decisions often are made by multidisciplinary teams partnering with patients. More patients and families also take on the role of gathering their own information about the safety and efficacy of various care pathways or institutional outcomes on which to base their healthcare decisions. Patients have easier access to more information, including outcomes data, reviews, and opinions, than would be available to former generations. Providers sense a stronger obligation of transparency in presenting available management options clearly, in concordance with principles of informed consent. ${ }^{27}$ Furthermore, institutional outcomes and comparisons often are publically available, motivating scrutiny of healthcare systems over what practices are pursued by their physicians. In this new environment, one may speculate whether the continuation of a high mortality procedure over a lower mortality option in the interest of theoretic long-term gain, as unfolded for the arterial switch, may be justifiable.

Ascertaining the public health benefit of a new procedure or medication, balanced against its risks, remains a difficult 
task even today. ${ }^{28}$ Belief in a favorable outcome often may predate objective evidence in such an outcome. There is recognition that early experience will mean at times poorer initial outcomes. ${ }^{29}$ The most unambiguous measure of successful adaptation is improved mortality. ${ }^{30}$ In the case of the arterial switch, therefore, with data showing poorer outcome even after midterm follow-up, as well as published caveats about high mortality of the arterial switch in inexperienced hands, ${ }^{20}$ it seems these criteria were initially overlooked in favor of other less-tangible but important expectations of outcome, and the arterial switch continued to roll out as the theoretic best option. Still, reported mortality 10 years after the first successful case was marginally higher than procedural mortality for the atrial switch. One recognizes that many other facets of patient care, including age at time of surgery, anatomic considerations, and various comorbidities, likely played a role in decision-making and surgical outcome for each individual. Yet overall, the strong belief in the long-term superiority of one technique over another did in fact win the day over the short-term realities.

The scholarly examination of surgical innovation itself is a fairly new undertaking. ${ }^{29}$ Surgical innovation has long stood apart from other healthcare practices because of the unforeseen need for intraoperative adaptation where there is no option for prior approval. Ethically, surgical innovation still demands informed patient consent whenever possible. ${ }^{31}$ Yet the somewhat unstated implication in the patient's consent is the surgeon's role to do the best he or she can with whatever unexpected findings or events are encountered. ${ }^{32}$ Under such circumstances, it is understood that the surgeon's adaptations will be ethically responsible and congruent with the patient's previously expressed wishes and goals, including long-term interests.

Yet, increased regulation of surgical innovation has been called for, recognizing that many innovations eventually show no advantage over conventional methods when investigated in properly controlled studies. ${ }^{33}$ If held to consensus recommendations about surgical innovation for today, ${ }^{34,35}$ the arterial switch operation in its first decade may have been subject to more scrutiny by local and national ethical committees and registry review, which would have needed, by one account, 28 years to show a clear survival benefit. ${ }^{23}$ The arterial switch experience shows that risk in the short term cannot be an apt comparator when the expected gains are long term. Healthcare providers revere the randomized control trial as the standard for assessing superiority of one approach over another. Yet, it is unlikely that the D-TGA question could have been answered with a randomized trial because of the required early experience to master the technique, the need for a long-term follow-up, and the frequent cross-over from one intended procedure to another. ${ }^{16}$

In this retrospective, we recognize inherent bias in the reported literature. Published series often were small and variable in their level of detail and included surgical experience from considerably earlier years than the date of publication. For example, it is not certain to what extent the timing of surgery may have influenced the reported outcome. Recent larger population data that include earlier eras suggest that operative mortality was higher than previous publications reported, indicative of publication bias. ${ }^{36}$ Further, it is not certain that all of these arterial switch fatalities would have survived if offered a Mustard/Senning; many nonsurvivors were those with complex anatomy, heterotaxy, or coexisting lesions in whom even an atrial switch would have proven difficult. Conversely, one could speculate that further improvements in atrial switch outcomes, even long term, may have continued had not the procedure been abandoned.

Despite these uncertainties, in our view it seems likely that many infants who did not survive an arterial switch procedure would have survived an atrial switch procedure. These then would reflect excess mortality from the arterial switch innovation and a learning-curve cost. That cost seems justified on the whole. The many who benefit from the arterial switch today, a fairly low-risk procedure with excellent long-term prospects, owe this option to those families whose infants died in the early days of the innovation.

\section{CONCLUSIONS}

From this experience, we should consider whether standards, safeguards, and formal scrutiny that have been built up around patient protection have become such that theoretic long-term benefit from new therapies, surgical or otherwise, could not be permissibly pursued when early data are not supportive. This could be a potential negative connotation of the type of ethical oversight that has slowly been added over time in society, despite being well intended and in the patient's interest. For example, it may be difficult to adopt an alternative strategy to the Fontan palliation for patients with single-ventricle physiology, a procedure with excellent intermediate outcome but extensive longterm morbidity and mortality, if that innovative surgical strategy could result in increased loss in life up front. As we hold ourselves accountable to ever increasingly high standards of healthcare outcome evaluation, not every question can or should be addressed with a randomized clinical trial. Long-term experience and retrospective comparisons still may be needed to bear out clinical decision making, particularly in the setting of surgical innovation.

\section{Conflict of Interest Statement}

Authors have nothing to disclose with regard to commercial support.

\section{References}

1. Dodge-Khatami A, Mavroudis C, Mavroudis CD, Jacobs JP. Past, present, and future of the arterial switch operation: historical review. Cardiol Young. 2012; 22:724-31. 
2. Konstantinov IE, Alexi-Meskishvili VV, Williams WG, Freedom RM, Van Praagh R. Atrial switch operation: past, present, and future. Ann Thorac Surg. 2004; 77:2250-8.

3. Mustard WT, Chute AL, Keith JD, Sirek A, Rowe RD, Vlad P. A surgical approach to transposition of the great vessels with extracorporeal circuit. Surgery. 1954;36:31-51.

4. Senning A. Surgical correction of transposition of the great vessels. Surgery. 1959;45:966-80.

5. Mustard WT, Keith JD, Trusler GA, Fowler R, Kidd L. The surgical management of transposition of the great vessels. J Thorac Cardiovasc Surg. 1964;48:953-8.

6. Horer J, Schreiber C, Cleuziou J, Vogt M, Prodan Z, Busch R, et al. Improvement in long-term survival after hospital discharge but not in freedom from reoperation after the change from atrial to arterial switch for transposition of the great arteries. J Thorac Cardiovasc Surg. 2009;137:347-54.

7. Breckenridge IM, Stark J, Bonham-Carter RE, Oelert H, Graham GR, Waterston DJ. Mustard's operation for transposition of the great arteries. Review of 200 cases. Lancet. 1972;1:1140-2.

8. Jatene AD, Fontes VF, Paulista PP, Souza LC, Neger F, Galantier M, et al, Anatomic correction of transposition of the great vessels. J Thorac Cardiovasc Surg. 1976;72:364-70.

9. Lecompte Y, Zannini L, Hazan E, Jarreau MM, Bex JP, Tu TV, et al. Anatomic correction of transposition of the great arteries. J Thorac Cardiovasc Surg. 1981:82:629-31.

10. Freedom RM, Culham JA, Olley PM, Rowe RD, Williams WG, Trusler GA. Anatomic correction of transposition of the great arteries: pre- and postoperative cardiac catheterization, with angiocardiography in five patients. Circulation. 1981;63:905-14.

11. Goor DA, Shem-Tov A, Neufeld HN. Impeded coronary flow in anatomic correction of transposition of the great arteries: prevention, detection, and management. J Thorac Cardiovasc Surg. 1982;83:747-54.

12. Kawabori I, Guntheroth WG, Morgan BC, Mohri H, Dillard DH. Surgical correction in infancy to reduce mortality in transposition of the great arteries. Pediatrics. 1977;60:83-5.

13. Piccoli GP, Wilkinson JL, Arnold R, Musumeci F, Hamilton DI. Appraisal of the Mustard procedure for the physiological correction of "simple" transposition of the great arteries. Eighty consecutive cases, 1970-1980. J Thorac Cardiovasc Surg. 1981;82:436-46.

14. Quaegebeur JM, Rohmer J, Ottenkamp J, Buis T, Kirklin JW, Blackstone EH, et al. The arterial switch operation. An eight-year experience. J Thorac Cardiovasc Surg. 1986;92:361-84.

15. Norwood WI, Dobell AR, Freed MD, Kirklin JW, Blackstone EH. Intermediate results of the arterial switch repair. A 20-institution study. J Thorac Cardiovasc Surg. 1988;96:854-63.

16. Castaneda AR, Trusler GA, Paul MH, Blackstone EH, Kirklin JW. The early results of treatment of simple transposition in the current era. J Thorac Cardiovasc Surg. 1988;95:14-28.

17. Rudra HS, Mavroudis C, Backer CL, Kaushal S, Russell H, Stewart RD, et al. The arterial switch operation: 25-year experience with 258 patients. Ann Thorac Surg. 2011;92:1742-6.

18. Yamaguchi M, Hosokawa Y, Imai Y, Kurosawa H, Yasui H, Yagihara T, et al. Early and midterm results of the arterial switch operation for transposition of the great arteries in Japan. J Thorac Cardiovasc Surg. 1990;100:261-9.
19. Fal'kovskii GE, Il'in VN, Kramer VS, Musatova TI, Kim AI. [Experience in the use of the Mustard operation in the surgical treatment of transposition of the great vessels]. Vestn Akad Med Nauk SSSR. 1989;52-6.

20. Merlo M, de Tommasi SM, Brunelli F, Abbruzzese PA, Crupi G, Ghidoni I, et al Long-term results after atrial correction of complete transposition of the great arteries. Ann Thorac Surg. 1991;51:227-31.

21. Gorler H, Ono M, Thies A, Lunkewitz E, Westhoff-Bleck M, Haverich A, et al. Long-term morbidity and quality of life after surgical repair of transposition of the great arteries: atrial versus arterial switch operation. Interact Cardiovasc Thorac Surg. 2011;12:569-74.

22. Massin MM. Midterm results of the neonatal arterial switch operation. A review J Cardiovasc Surg. 1999;40:517-22.

23. Bull C, Yates R, Sarkar D, Deanfield J, de Leval M. Scientific, ethical, and logistical considerations in introducing a new operation: a retrospective cohort study from paediatric cardiac surgery. BMJ. 2000;320:1168-73.

24. Jacobs JP, Jacobs ML, Mavroudis C, Chai PJ, Tchervenkov CI, LacourGayet FG, et al. Transposition of the great arteries: lessons learned about patterns of practice and outcomes from the Congenital Heart Surgery Database of the Society of Thoracic Surgeons. World J Pediatr Congenit Heart Surg. 2011;2:19-31.

25. Leon-Wyss J, Lo Rito M, Barnoya J, Castaneda AR. Persistent institutional difficulties in surgery for transposition of the great arteries in Guatemala: analysis with the Aristotle basic and comprehensive scores. World J Pediatr Congenit Heart Surg. 2011;2:346-50.

26. Schidlow DN, Jenkins KJ, Gauvreau K, Croti UA, Giang DT, Konda RK, et al Transposition of the great arteries in the developing world: surgery and outcomes. J Am Coll Cardiol. 2017;69:43-51.

27. Neff MJ. Informed consent: what is it? Who can give it? How do we improve it? Respir Care. 2008;53:1337-41.

28. Massol J, Puech A, Boissel JP, Participants inRound Table No GX. How to anticipate the assessment of the public health benefit of new medicines? Therapie 2007;62:427-35.

29. Riskin DJ, Longaker MT, Gertner M, Krummel TM. Innovation in surgery: a historical perspective. Ann Surg. 2006;244:686-93.

30. Ergina PL, Cook JA, Blazeby JM, Boutron I, Clavien PA, Reeves BC, et al. Challenges in evaluating surgical innovation. Lancet. 2009;374:1097-104.

31. Angelos P. Ethics and surgical innovation: challenges to the professionalism of surgeons. Int J Surg. 2013;11(Suppl 1):S2-5.

32. Angelos $P$. The ethical challenges of surgical innovation for patient care. Lancet 2010;376:1046-7.

33. Biffl WL, Spain DA, Reitsma AM, Minter RM, Upperman J, Wilson M, et al; Society of University Surgeons Surgical Innovations Project T. Responsible development and application of surgical innovations: a position statement of the Society of University Surgeons. J Am Coll Surg. 2008;206:1204-9.

34. McCulloch P, Altman DG, Campbell WB, Flum DR, Glasziou P, Marshall JC, et al. No surgical innovation without evaluation: the IDEAL recommendations. Lancet. 2009:374:1105-12.

35. Reitsma AM, Moreno JD. Ethics of innovative surgery: US surgeons' definitions, knowledge, and attitudes. J Am Coll Surg. 2005;200:103-10.

36. Vejlstrup N, Sorensen K, Mattsson E, Thilen U, Kvidal P, Johansson B, et al. Long-term outcome of Mustard/Senning correction for transposition of the great arteries in Sweden and Denmark. Circulation. 2015;132:633-8. 